\title{
IMPACTO DE CHOQUES MACROECONÔMICOS SOBRE OS NIVEIS DE POLUIÇÃO INDUSTRIAL NO BRASIL ${ }^{1}$
}

\author{
Henrique Tomé da Costa Mata ${ }^{2}$ \\ José Euclides Alhadas Cavalcanti ${ }^{3}$
}

Resumo - Neste artigo, o problema da poluição industrial é tratado como uma variável endógena ao Modelo de Insumo-Produto Ampliado. No estudo foram estimadas quantidades de diferentes poluentes da água e do ar, com base em dados IPPS do Banco Mundial, elaborados especificamente para este tipo de pesquisa. O modelo analítico proposto por Wassily Leontief foi operacionalizado e consistiu-se de uma versão ampliada da matriz de insumo-produto clássica aplicada à análise ambiental. Os resultados obtidos indicaram que os sólidos totais em suspensão, com 942.872 ton., SO2, com 803.280 ton., NO2, com 477.572 ton., $\mathrm{CO}$, com 414.323 ton. e partículas totais, com 368.791 ton. constituíram as cinco categorias de poluentes dominantes na estrutura industrial brasileira, todas pertencentes à classe de poluentes do ar. Foram identificadas cinco indústrias dinâmicas na emissão de poluentes no Brasil. A siderurgia e metalurgia, outras indústrias, química e petroquímica, madeira, mobiliário, papel e celulose, e materiais eletroeletrônicos, cujos expressivos multiplicadores de emissão de poluentes são resultantes de choques na demanda final. Os setores mais dinâmicos da economia foram também os mais dinâmicos na emissão de poluentes.

Palavras-chave: Poluição, crescimento econômico e modelo de insumo-produto.

\footnotetext{
${ }^{1}$ Extrato da tese de doutorado em Economia Aplicada elaborada pelo autor e orientado pelo co-autor.

${ }^{2}$ D.S. em Economia Aplicada, Professor do Departamento de Ciências Econômicas da Universidade Estadual de Santa Cruz - UESC, km, 16, Ilhéus - BA. CEP 45600-000. E-mail: hnrmata@ hotmail.br

${ }^{3}$ PhD. em Economia, Professor do Centro Universitário de Ciências Gerenciais - UNA. Endereço: Rua Aimorés, 1451 - Lourdes. Belo Horizonte - MG. CEP 30140-071 E-mail: jeuclid@ufv.br Recebido em 25/04/2003 Aceito em 02/06/2003
} 


\section{Introdução}

O desempenho de varáveis econômicas em níveis micro e macroeconômico, como juros, câmbio, inflação, competitividade e crescimento, determina, de forma estrutural, o comportamento de variáveis ambientais, razão por que o comportamento dos indicadores ambientais de um sistema econômico deve ser tratado de forma endógena. $\mathrm{O}$ administrador público pode, dentro de determinados limites, buscar atingir níveis de equilíbrio econômico consistentes com as metas de sustentabilidade ambiental. Nessa perspectiva, destacam-se a relevância e a atualidade de novos métodos da análise econômica que levem em conta a interdependência dos fatores econômicos e ambientais.

Implícito aos fatores ambientais existe um conjunto de variáveis que se distribuem no campo da economia dos recursos naturais e no de economia da poluição. No primeiro, abordam-se o sistema como fonte de energia e outros recursos materiais essenciais e, no segundo, o sistema é simultaneamente receptor de energia dissipante e outros componentes residuais. A contextualização das duas abordagens reflete-se no complexo de correntes teóricas que buscam conciliar a estabilidade com a persistência reprodutiva do sistema econômico.

Embora se admitam complementaridades entre essas diferentes abordagens, elas diferem entre si no enfoque específico e servem de base para descrição das condições reais e potenciais de crescimento econômico.

A dinâmica da economia associa-se, geralmente, às mudanças de trajetórias de atividades primárias para as atividades secundárias, de forte base industrial. A evolução desse mecanismo ocorre com crescente declínio da estabilidade ambiental, causado, principalmente, pela emissão de resíduos poluentes. Assim, à medida que a participação do setor industrial no Produto Interno Bruto se expande, questionam-se os diferentes cenários de emissões de poluentes, especialmente das vantagens potenciais que decorrem das possibilidades do novo mecanismo de comércio de cotas, entre muitos benefícios diretos e indiretos. Permite-se, 
no plano de negociações internacionais, a compra de "cotas de redução" por países que ultrapassem as metas estabelecidas para emissão. A adoção de estratégias de desenvolvimento industrial pode criar condições para a venda dessas cotas, além de gerar dividendos externos sem necessidade de redução da atividade industrial. Portanto, a introdução de novos instrumentos econômicos na administração e no controle ambiental deve estar relacionada com a verificação permanente dos impactos da atividade econômica na intensidade de poluição, no que se inserem os objetivos deste artigo.

Na primeira parte, faz-se rápida resenha sobre a importância, a justificativa e o objetivo do atrigo. Em seguida, esquematiza-se a fundamentação teórico-analítica que serviu de base à implementação do modelo e à análise dos resultados. Na terceira fase, apresentam-se os resultados e discussões, em termos de estimativas de poluentes emitidos e de impacto de diferentes choques de política econômica sobre o nível de emissões. Seguem-se, finalmente, as considerações finais.

\section{Metodologia}

\subsection{Modelo teórico e analítico}

A literatura vem salientando, entre outros procedimentos, a necessidade de se implementar um instrumental analítico que considere a questão ambiental intrínseca à atividade econômica. O modelo de Insumo-Produto Ampliado, proposto pelo prof. Wassily Leontief em 1970, presta-se, teórica e analiticamente, a este objetivo. O modelo e sua base teórica consistem da versão aplicada em análises de equilíbrio geral e pode ser estruturado para considerar a internalização de setores geradores e de controle da poluição industrial. Ressaltam-se, porém, as dificuldades decorrentes de sua efetiva implementação empírica, dada a enorme falta de dados estatísticas disponíveis nessa linha de pesquisa. 
Em princípio, Leotief, 1970; 1974; Victor, 1972; e Richardson, 1972, definiram os componentes de demanda final agregada como variável exógena, o que confere certo grau de flexibilidade à análise, de tal forma que, em termos formais, a formulação geral simplificada parte da expressão inicial que descreve um quadro econômico de insumo-produto clássico:

$$
X_{i}=\sum_{j=1}^{n} X_{i j}+\left(C_{i}+I_{i}+G_{i}+E_{i}\right) \text {, }
$$

em que $X_{\mathrm{ij}}$ é a produção do setor i utilizada como insumo intermediário no setor j; e $C_{i}, I_{i}, G_{i}, E_{i}$, e $X_{i}$ são, respectivamente, as despesas totais gastas com o produto do setor i pelas famílias, com a finalidade de consumo; a produção do setor i que se destina ao investimento; a produção do setor i que é adquirida pelo governo; a produção do setor i que é destinada à exportação. $\mathrm{O}$ somatório dos setores $\mathrm{C}_{\mathrm{i}}, \mathrm{I}_{\mathrm{i}}$ e $\mathrm{G}_{\mathrm{i}}$ constitui a demanda final doméstica, ou a absorção interna que, somada $\mathrm{E}_{\mathrm{i}}$, forma a demanda final do setorial, $Y_{i}$. A suposição básica, dada em (2) é de que o consumo intermediário seja uma proporção fixa da quantidade total de cada produto, uma restrição de curto prazo, sobre a qual, para os planos da pesquisa, é irrelevante entrar em pormenores, tendo em vista o grande desconhecimento que ainda impera no binômio econômico e ambiental.

Tem-se

$$
X_{i}=, \sum_{j=1}^{n} a_{i j} x_{j}+Y_{i}
$$

em que $\mathrm{a}_{\mathrm{ij}}$ é o coeficiente técnico de produção e reflete a relação técnica existente no sistema; $a_{i j} x_{j}$ determina a quantidade de produto do setor $\mathrm{i}$ necessário à produção de uma unidade de produção no setor j; e $\mathrm{Y}_{\mathrm{i}}$ é a demanda final agregada de produtos no setor $\mathrm{i}$, tal que $\mathrm{Y}_{\mathrm{i}}=\mathrm{C}_{\mathrm{i}}+\mathrm{I}_{\mathrm{i}}+\mathrm{G}_{\mathrm{i}}+\mathrm{E}_{\mathrm{i}}$.

Tratando-se de uma abordagem matricial, a análise do lado das colunas mostra as compras de insumos intermediários, produzidos pela indústria $\mathrm{j}$, por todas as outras indústrias. As partes componentes do setor de pagamentos representam o pagamento, pelos $\mathrm{j}$ setores, ao trabalho e por 
todos os outros itens do valor adicionado, como serviços do governo, remuneração de capital (pagamentos de taxas e juros), massa salarial e lucros. Em adição, as importações de insumos são embutidas no setor de remuneração de fatores e denota $M_{j}$. Somando a coluna j, obtém-se:

$$
X_{j}=\sum_{i}^{n} X_{i j}+L_{j}+V_{j}+M_{j}, \quad i=1,2, \ldots, n
$$

em que $X_{j}$ é a produção total do setor $\mathrm{j} ; \mathrm{L}_{\mathrm{j}}$, valor do trabalho, pago pelo setor $\mathrm{i}$, na produção do setor $\mathrm{j} ; \mathrm{V}_{\mathrm{j},}$ outros valores adicionados, pagos pelo setor $\mathrm{i}$, na produção do setor $\mathrm{j}$; M, importações do setor i para a produção do setor $\mathrm{j}$. A soma total de cada linha $\left(\mathrm{X}_{\mathrm{i}}\right)$ e de cada coluna $\left(\mathrm{X}_{\mathrm{j}}\right)$ resulta no produto bruto total da economia $(\mathrm{X})$, simultaneamente, em termos de produção, e renda, em termos das despesas e custos. Na forma matricial, tem-se a seguinte expressão geral:

$$
\mathrm{X}=\mathrm{AX}+\mathrm{Y} \text {, }
$$

em que $\mathrm{X}$ é de dimensão ( $\mathrm{n}$ x 1), com a produção total de cada setor; Y é de dimensão $\mathrm{n}$ x 1, com a demanda final setorial; e A é de dimensão $\mathrm{n}$ $\mathrm{x} n$, com os coeficientes das relações interindustriais. Visto que a demanda é considerada componente exógeno na estrutura em análise, a produção total setorial será obtida da solução seguinte:

$$
X_{i}=\left(\mathbf{I}-\mathbf{A}_{\mathrm{ij}}\right)^{-1} Y_{\mathrm{i}} \text {, }
$$

em que a expressão (I-A) ${ }^{-1}$ é a matriz $\mathbf{n} \mathbf{x} \mathbf{n}$ que contém os coeficientes da relação dos impactos diretos e indiretos nos setores. Segundo Leontief (1970), essa análise descreve e explica o nível de produção setorial em termos de sua relação com o nível da atividade em todos os outros setores da economia. Essa fundamentação é bastante plausível à análise da poluição industrial, dado o caráter de dependência interna e de tecnologia no sistema produtivo. Assim, o modelo permite a determinação do nível da atividade econômica em cada setor produtivo como função de choques exógenos na demanda final. 
Segundo Miller e Blair (1985), em análises de poluição associadas às atividades industriais, geralmente admite-se um conjunto de coeficientes técnicos de impactos ambientais diretos, como as medidas de geração de poluentes e a emissão de resíduos sólidos numa matriz do tipo $\mathbf{V}=$ $\left[\mathbf{v}_{\mathbf{k j}}\right]$, em que cada elemento de $\mathbf{V}$ meça a quantidade de poluentes $\mathrm{k}$, gerados por valor da produção na indústria j. Isso pressupõe o domínio razoável das relações técnicas e ambientais que prevalecem o sistema. Desse modo, o vetor do nível de poluição total será dado por $\mathbf{v}^{*}=\mathbf{v} \cdot \mathbf{X}$, sendo $\mathbf{X}$, o vetor do nível de produção industrial total. Da relação clássica já descrita obtém-se o vetor do nível de poluição, como uma função de demanda final, como segue:

$$
\mathbf{V}^{*}=\left[\mathbf{v} \cdot(\mathbf{I}-\mathbf{A})^{-1}\right] \mathbf{Y},
$$

em que [ $\left.\mathbf{v} \cdot(\mathbf{I}-\mathbf{A})^{-1}\right]$ passa a definir a matriz dos coeficientes totais da economia com emissão de poluição. Os elementos dessa matriz representam os requisitos diretos e indiretos totais de poluição.

De forma operacional, a formulação proposta por Leontief (1970), para a análise dos efeitos de geração e controle da poluição, consiste na expansão da matriz dos coeficientes técnicos clássicos para introduzir coeficientes que sintetizam produção industrial e emissão ou eliminação de poluentes. No caso de geração de poluição, os coeficientes refletem quantidades de cada tipo de poluente por unidade de produção industrial, e, de forma semelhante, os coeficientes de redução devem refletir as atividades de eliminação setorial de poluição. O Quadro 1 ilustra o esquema desta abordagem.

Quadro 1 - Quadro analítico expandido do fluxo de transação insumoproduto para análise de geração e controle de poluição

\begin{tabular}{l||ccc||cc}
\hline \hline & $\begin{array}{c}\text { Setor } \\
\text { Indústria }\end{array}$ & $\begin{array}{c}\text { Setor } \\
\text { Serviços }\end{array}$ & $\begin{array}{c}\text { Redução } \\
\text { Poluição }\end{array}$ & $\begin{array}{c}\text { Demanda } \\
\text { Final }\end{array}$ & $\begin{array}{c}\text { Produção } \\
\text { Total }\end{array}$ \\
\hline \hline $\begin{array}{l}\text { Setor Indústria } \\
\begin{array}{l}\text { Setor Serviços } \\
\text { Geração Poluição }\end{array}\end{array}$ & $\mathbf{Z}_{\mathbf{1 , 2}}$ & $\mathbf{Z}_{\mathbf{i}, \mathbf{j}}$ & $\mathbf{Z}_{\mathbf{P i}}$ & $\mathbf{Y}_{\mathbf{i}}$ & $\mathbf{X}_{\mathbf{i}}$ \\
\hline \hline
\end{tabular}

Fonte: Miller e Blair, 1985. 
A análise do Quadro 1 desenvolve-se com base na estrutura clássica de insumo-produto, em que $\mathbf{A}_{\mathbf{p}}=\mathbf{Z}_{\mathbf{p}}$ (constitui a solução geral e $\mathbf{A}_{\mathbf{p}}$, a matriz dos coeficientes técnicos. A última linha de $\mathbf{A} \mathbf{p}_{\mathbf{i j}}$ representa, nesse caso, a geração de poluentes por setor econômico. Daí, $\mathbf{X}_{\mathbf{p}}=\left(\mathbf{I}-\mathbf{A}_{\mathbf{p}}\right)^{-1} \mathbf{Y}_{\mathbf{p}}$ define a matriz expandida de Leontief, para a análise de externalidade ambiental decorrente da emissão de poluentes.

De acordo com Lee (1982), Miernyk (1974) e Hawkins e Simon (1949), o aspecto teórico importante para o desenvolvimento da proposta deste estudo prende-se às condições de estabilidade relativas às soluções finais consistentes. Esse aspecto tem sido fruto de inúmeros debates científicos em torno da modelagem empírica do modelo. Argumenta-se que os coeficientes técnicos diretos de solução final devam atender a certas condições de estabilidade, para que reflitam o quadro consistente de resultados. Os requisitos essenciais desta abordagem representam as propriedades de Hawkins-Simon, sobre a existência e unicidade da solução final, conforme Dorfman et al., 1964; Solow, 1952; Hawkins e Simon, 1949 e Bulmer-Thomas, 1982. Analiticamente, essas propriedades são resumidas no contexto em que, dada a complexidade de operacionalização do modelo de insumo-produto ambiental, a existência de soluções nãonegativas que garantam consistência dos resultados finais é fundamentalmente importante. Baseado em Miller e Blair (1985), demonstra-se que o modelo ampliado para conter setores de geração e, ou, a eliminação de poluentes é derivado, diretamente, das condições originais de estabilidade de Hawkins-Simon.

A estrutura matricial usada na pesquisa e que satisfez à internalização das estimativas de poluentes gerados e dos custos de controle é dada por

$$
\left[\begin{array}{cccc}
1-\mathrm{a}_{11} & -\mathrm{a}_{12} & \ldots & -\mathrm{a}_{1 \mathrm{p}} \\
-\mathrm{a}_{21} & 1-\mathrm{a}_{22} & \ldots & -\mathrm{a}_{2 \mathrm{p}} \\
\ldots & \ldots & \ldots & \ldots \\
\mathrm{a}_{\mathrm{p} 1} & -\mathrm{a}_{\mathrm{p} 2} & \ldots & 1-\mathrm{a}_{\mathrm{pp}}
\end{array}\right]\left[\begin{array}{c}
\mathrm{X}_{1} \\
\mathrm{X}_{2} \\
\ldots \\
\mathrm{X}_{\mathrm{p}}
\end{array}\right]=\left[\begin{array}{c}
\mathrm{Y}_{1} \\
\mathrm{Y}_{2} \\
\cdots \\
-\mathrm{Y}_{\mathrm{p}}
\end{array}\right] .
$$


Essa relação pode ser apresentada, em termos de submatrizes componentes, em (8a) e (8b):

$$
\begin{aligned}
& {\left[\begin{array}{cc}
1-a_{11} & -a_{12} \\
-a_{21} & 1-a_{22}
\end{array}\right]\left[\begin{array}{l}
X_{1} \\
X_{2}
\end{array}\right]+\left[\begin{array}{l}
-a_{1 p} \\
-a_{2 p}
\end{array}\right] \cdot\left[X_{p}\right]=\left[\begin{array}{c}
Y_{1} \\
Y_{2}
\end{array}\right]}
\end{aligned}
$$

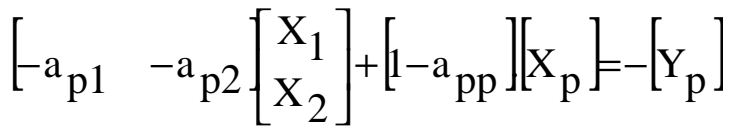

Da expressão (8a), a matriz $\left[\begin{array}{cc}1-\mathrm{a}_{11} & -\mathrm{a}_{12} \\ -\mathrm{a}_{21} & 1-\mathrm{a}_{22}\end{array}\right]$ representa $(\mathbf{I}-\mathbf{A})$, que é a matriz estrutural de Leontief, sem variáveis ambientais. Essa matriz, estrutural em si, satisfaz àquelas propriedades por causa das características intrínsecas dos coeficientes técnicos. A partir da equação (8a) obtém-se a solução geral de X, como valor da produção total da economia,

$$
\left[\begin{array}{l}
X_{1} \\
X_{2}
\end{array}\right]=(I-A)^{-1}\left\{\left[\begin{array}{c}
Y_{1} \\
Y_{2}
\end{array}\right]+\left[\begin{array}{c}
a_{1 p} \\
a_{2 p}
\end{array}\right] \cdot\left[X_{p}\right]\right\}
$$

$\mathrm{O}$ argumento é mostrar que todos os elementos de $\mathrm{X}=\left[\begin{array}{c}X_{1} \\ X_{2}\end{array}\right]$ são positivos. Como os componentes da matriz estrutural satisfazem à condição de Hawkins-Simon, todos os elementos da matriz dos requerimentos diretos e indiretos, de Leontief, (I-A) ${ }^{-1}$, também serão positivos.

Por outro lado, $Y=\left[\begin{array}{c}Y_{1} \\ Y_{2}\end{array}\right]$ representa o vetor de demanda final da economia, e todos os seus elementos são estritamente não-negativos. 
Os elementos $\mathbf{a}_{1 \mathbf{p}}$ e $\mathbf{a}_{\mathbf{2 p}}$ representam os insumos de outros setores, em termos de valor solicitados para as despesas de controle de poluição, e podem ser tratados como custo de controle. Esses elementos também têm valores não-negativos, já que são valores monetários. Partindo-se da prova de que os elementos de $\mathbf{X}$ são não-negativos, a não-negatividade de $\mathbf{X}_{\mathbf{p}}$, que é a quantidade total de poluição controlada, pode ser deduzida da solução da equação (8b), obtendo-se

$$
X_{p}=\left(1-a_{p p}\right)^{-1}\left\{\left[\begin{array}{ll}
a_{p 1} & a_{p 2}
\end{array}\right] \cdot\left[\begin{array}{l}
X_{1} \\
X_{2}
\end{array}\right]-\left[Y_{p}\right]\right\}
$$

em que $\mathbf{a}_{\text {pp }}$ descreve os poluentes emitidos, que é associada às atividades de controle. Isso quer dizer que a quantidade de poluição gerada pelo setor de controle deve ser menor que a quantidade eliminada para que $\mathbf{a}_{\mathrm{pp}}$ seja menor que a unidade e exista $\left(\mathbf{1}-\mathbf{a}_{\mathbf{p p}}\right)^{-\mathbf{1}}$. Finalmente, $\mathbf{X}_{\mathbf{p}}$ será

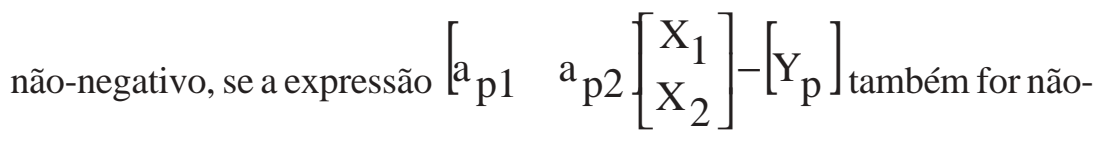
negativa, isto é, se $\left[\begin{array}{ll}a_{p} 1 & a_{p} 2\end{array}\left[\begin{array}{l}X_{1} \\ X_{2}\end{array}\right]>\left[Y_{p}\right]\right.$. Nessa expressão, $\mathbf{Y}_{\mathbf{p}}$ representa a quantidade de poluição não eliminada ou tolerada na coluna de demanda final por setor de geração e tem valor negativo para satisfazer à identidade das contas na tabela de insumo-produto; e $\mathbf{a}_{\mathbf{1 p}}$ e $\mathbf{a}_{\mathbf{2 p}}$ são quantidades estimadas de poluentes que foram gerados por valor de produção $\mathbf{X}_{1}$ e $\mathbf{X}_{2}$, respectivamente. Com $\mathbf{X p}$ não-negativo, a condição é satisfeita para a versão ambiental proposta por Leontief e usada como modelo referencial analítico na pesquisa. O raciocínio implícito na demonstração é de que o modelo utilizado é empiricamente consistente. 


\subsection{Fonte e tratamento de dados}

Os dados econômicos básicos foram obtidos das Tabelas de InsumoProduto da Matriz Intersetorial Brasileira de 1995, elaboradas pela Fundação Instituto Brasileiro de Geografia e Estatísitca, IBGE. Dados específicos sobre cargas de poluentes (DBO, metais e partículas, $\mathrm{SO}_{2}, \mathrm{NO}_{2}$, $\mathrm{HC}$ e $\mathrm{CO}$ ) foram estimados com base nos Índices de Intensidade de Poluição Industrial do Sistema IPPS ${ }^{4}$, do WORLD BANK. O Projeto de Pesquisa sobre o Controle de Poluição Industrial, do Banco Mundial, desenvolveu a base de dados e técnicas que permitem estimar quantidades de poluentes e custos de controle baseados nos indicadores de escala industrial. O sistema, chamado de "Industrial Pollution Projection System" (IPPS), tem sido usado nas pesquisas sobre poluição industrial do Banco Mundial, assim como em outras instituições internacionais de pesquisa. O procedimento IPPS fundamenta-se na utilização de dados sobre o valor da produção industrial para estimar perfis de emissão de poluentes. Com base em levantamentos sobre três variáveis econômicas (nível de emprego, valor adicionado e valor da produção), o sistema IPPS permite a conversão desses dados em medidas estimativas da intensidade de poluição (Hettige et al., 1994). Esses coeficientes obedecem ao Padrão de Classificação Industrial, ISIC, e permitem estimativas da intensidade de $\mathbf{S O}_{2}, \mathbf{N O}_{2}$, $\mathbf{C O}$, Compostos Orgânicos Voláteis $(\mathbf{C O V})$, Partículas em Suspensão (TSS), Demanda Bioquímica de Oxigênio (BDO), sólidos em suspensão (TSS) e Metais Tóxicos.

Em relação à agregação de dados, maior relevância foi dada àqueles setores importantes do ponto de vista de geração de poluentes, o que levou à determinação de doze grandes agregados setoriais cuja estrutura é composta de agropecuária, extrativo mineral, têxteis, couros e calçados, alimentos processados, siderurgia e metalurgia, madeira, papel e celulose, química e petroquímica, outras indústrias, materiais eletroeletrônicos, transportes e máquinas, farmacêutica e veterinária e comércio e serviços.

${ }^{4}$ A descrição do método IPPS é baseada em "Policy Research Working Paper \# 1431 (Part 1), do Banco Mundial, intitulado: The industrial pollution projection system, de autoria de Hettige et. al., (1994). 


\section{Resultados e discussões}

\subsection{Estimativa de poluição}

Levantamentos sistemáticos das emissões de diferentes tipos de poluentes industriais são ainda insuficientes no Brasil, embora algumas agências ambientais, em nível estadual e nacional, venham despendendo esforços para a construção de uma base de dados operacional para análises de políticas públicas específicas. Desse modo, estimativas do nível das emissões brasileiras foram realizadas com base em dados secundários indiretos do sistema IPPS, do Banco Mundial, que associa a emissão de poluentes ao valor da produção, ao valor adicionado e ao nível de emprego de cada atividade industrial. Para isso, como a intensidade ${ }^{4}$ de poluição que constitui a base do sistema IPPS refere-se ao ano de 1987, para a economia dos Estados Unidos da América, os valores relativos à produção bruta brasileira foram convertidos para aquele ano-base, utilizando-se do deflator implícito do PIB brasileiro e da taxa média cambial no período. Embora as estruturas de preço e quantidades fossem diferentes, a recomendação técnica sobre o uso da Base de Dados do IPPS é de que esses indicadores possam ser aplicados em outras economias, já que se considera pouco relevante diferença na tecnologia de produção e na composição de produto no período. Vieses que possam ocorrer no processo de conversão não alterariam, significativamente, os resultados esperados.

O Quadro 2 apresenta as estimativas por tipo de poluente, em 1995, para o Brasil. Os resultados referentes às emissões por categoria se distribuem em nove agregados setoriais, uma vez que a agropecuária, o extrativo mineral e comércio e serviços não satisfazem à nomenclatura do International Standard Industrial Classification.

As emissões de poluentes ao ar, principalmente à base de enxofre, $\mathbf{S O}_{2}$, foram maiores nos agregados de outras indústrias, com 389.650 ton.;

\footnotetext{
${ }^{4}$ A intensidade de poluição consiste da estimativa setorial de poluição por unidade de produção, ou a poluição por unidade de atividade industrial.
} 
siderurgia e metalurgia, com 167.139 ton.; e química e petroquímica, com 133.016 ton. Dentre os doze setores agregados, o setor eletroeletrônico foi o que apresentou a menor quantidade de emissões de $\mathbf{S O}_{2}$, com 1.362 ton. Deve-se notar que, na análise complementar sobre a caracterização da estrutura produtiva, os setores siderurgia e metalurgia, química e petroquímica foram identificados como setores-chave da economia. Isso demonstra que os setores mais dinâmicos da economia são também geradores potenciais de poluição.

Quadro 2 - Emissões estimadas por componentes de poluição industrial (1.000 kg)

\begin{tabular}{lrrrrr}
\hline \multicolumn{1}{c}{ ATIVIDADE } & \multicolumn{1}{c}{ SO2 } & NO2 & \multicolumn{1}{c}{ CO } & VOC & \multicolumn{1}{c}{ PF } \\
\hline \hline Têxteis, couros, vestuários e calçados & 7.176 & 4.575 & 1.445 & 11.450 & 11 \\
Alimentos processados & 39.459 & 25.472 & 8.214 & 28.166 & 11.10 \\
Siderurgia e metalurgia & 167.139 & 31.911 & 135.370 & 17.988 & 20.22 \\
madeira, papel, celulose e gráfica & 28.494 & 18.158 & 37.487 & 18.632 & 3.259 \\
Química e petroquímica & 133.016 & 101.542 & 169.935 & 82.792 & 5.838 \\
Outras industrias & 389.650 & 278.430 & 46.637 & 24.250 & 321.033 \\
Materiais eletro-eletrônicos & 1.362 & 2.520 & 2.767 & 6.799 & 572 \\
Transp., máquinas e equipamentos & 33.962 & 13.202 & 12.090 & 37.398 & 822 \\
Farmacêutica e veterinário & 3.021 & 1.762 & 377 & 1.434 & 270 \\
\hline \hline Total por componente & $\mathbf{8 0 3 . 2 8 0}$ & $\mathbf{4 7 7 . 5 7 2}$ & $\mathbf{4 1 4 . 3 2 3}$ & $\mathbf{2 2 8 . 9 1 0}$ & $\mathbf{3 6 3 . 2 3 8}$ \\
\hline \hline
\end{tabular}

Fonte: Dados da pesquisa elaborados a partir dos índices de intensidade de poluição do IPPS obtidos da base de dados do Banco Mundial (Hettige et al., 1994).

\begin{tabular}{lrrrrr}
\hline \hline \multicolumn{1}{c}{ ATIVIDADE } & PTS & BDO & TSS & $\begin{array}{c}\text { Poluentes } \\
\text { Tóxicos }\end{array}$ & $\begin{array}{c}\text { Metais } \\
\text { Tóxicos }\end{array}$ \\
\hline \hline Têxteis, couros, vest. e calçados & 2.625 & 896 & 1.801 & 26.467 & 1.293 \\
Alimentos processados & 27.865 & 26.159 & 24.735 & 4.315 & 82 \\
Siderurgia e metalurgia & 36.010 & 8.431 & 663.760 & 62.853 & 32.322 \\
madeira, papel, celulose e gráfIca & 12.663 & 13.259 & 44.470 & 12.106 & 81 \\
Química e petroquímica & 31.147 & 10.618 & 42.224 & 136.741 & 4.889 \\
Outras industrias & 249.947 & 138 & 144.924 & 16.715 & 2.740 \\
Materiais eletroeletrônicos & 824 & 59 & 84 & 12.260 & 1.040 \\
Transp., máquinas e equipamentos & 6.922 & 38 & 563 & 19.832 & 1.955 \\
Farmacêutica e veterinário & 788 & 225 & 20.310 & 6.125 & 72 \\
\hline \hline Total por componente & $\mathbf{3 6 8 . 7 9 1}$ & $\mathbf{5 9 . 8 2 1}$ & $\mathbf{9 4 2 . 8 7 2}$ & $\mathbf{2 9 7 . 4 1 3}$ & $\mathbf{4 4 . 4 7 4}$ \\
\hline \hline
\end{tabular}

Fonte: Dados da pesquisa, elaborados a partir dos índices de intensidade de poluição do IPPS obtidos da base de dados do Banco Mundial (Hettige et al., 1994). 
Os óxidos de nitrogênio, $\mathbf{N O}_{2}$, mostram maiores níveis de emissões no agregado de outras indústrias, de química e petroquímica, de siderurgia e metalurgia, respectivamente, com 278.430, 101.542 e 31.911 ton. de poluentes, ou seja, em conjunto, representaram $86,25 \%$ dos lançamentos de $\mathbf{N O}_{2}$ ao ar. Em relação aos compostos orgânicos voláteis, os setores de química e petroquímica, transportes e máquinas e de alimentos processados apresentaram as maiores concentrações, com 36\%, 16\% e $12 \%$, respectivamente. No que se refere às emissões de óxido de carbono, os setores de química e petroquímica e de siderurgia e metalurgia foram os maiores emissores, visto que detiveram, respectivamente, $41 \%$ e $32,7 \%$ dos lançamentos totais, tendo sido observado, ainda, o mesmo comportamento nas emissões de partículas finas. Pesquisas desenvolvidas por Seroa da Motta et al. (1993) demonstraram também que as emissões de monóxido de carbono, $\mathbf{C O}$ são mais concentradas no setor de metalurgia, com aproximadamente $95 \%$ de emissões. Em relação à emissão de poluentes tóxicos, tais como metais tóxicos e outras partículas, os mesmos setores se mostraram relevantes. Estes resultados constituem indicadores importantes para adoção e desenvolvimento de políticas regulatórias e de controle de poluição do ar, no âmbito dos programas de desenvolvimento industrial brasileiro.

Quanto aos poluentes da água, a predominância que se registrou em torno dos setores de química e petroquímica e siderurgia e metalurgia, relativa a poluentes do ar, foi alterada para um novo perfil de distribuição. A estimativa de cargas orgânicas, dada pela demanda bioquímica de oxigênio, BDO, mostra que os setores de alimentos processados, com $43 \%$, madeira, mobiliário, papel e celulose, com $22 \%$, e química e petroquímica, com $17,7 \%$, foram importantes fontes de poluição da água. Em relação aos sólidos totais em suspensão na água, TSS, os setores de siderurgia $(70,4 \%)$, outras indústrias $(15,4 \%)$, madeira, mobiliário, papel e celulose $(4,7 \%)$ constituíram a base dos lançamentos, visto que absorveram $90,5 \%$ das emissões totais. A Figura 1 reporta o quadro resumo deste perfil de emissões totais estimado na economia brasileira. 


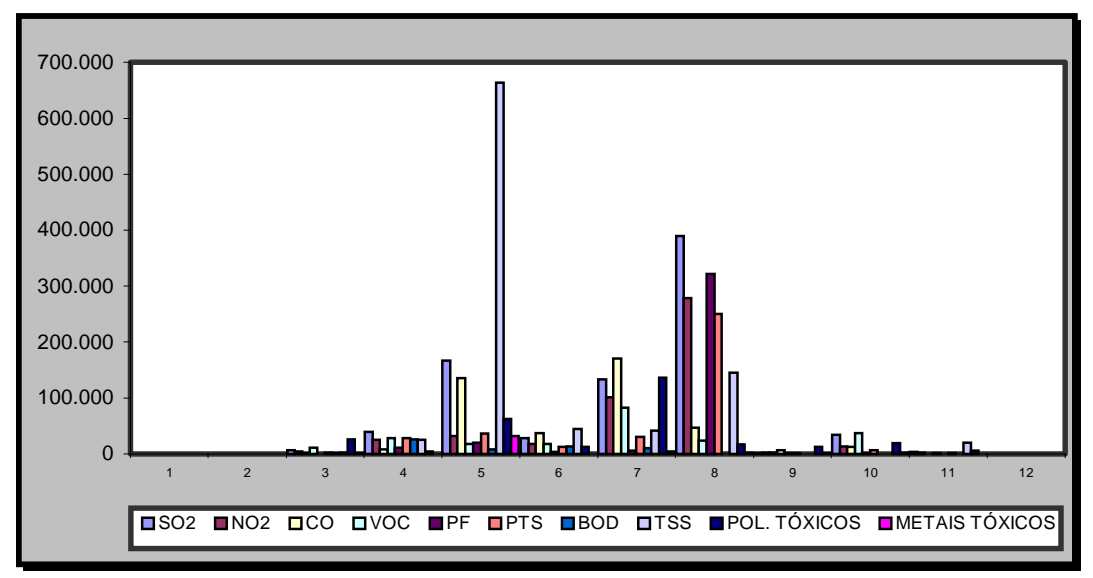

Figura 1 - Perfil das emissões totais de poluentes industriais no Brasil, em 1995.

\subsection{Impacto de choques macroeconômicos nos níveis das emissões setoriais}

Para analisar os impactos da atividade econômica nos níveis de emissões de diferentes tipos de poluentes, os coeficientes técnicos da poluição estimados foram inseridos, de forma endógena, à matriz de insumoproduto. O Quadro 3 apresenta efeito multiplicador resultante de choques da demanda final sobre os níveis de diferentes componentes da poluição. Deve-se observar que, embora os setores agropecuários, extrativos minerais e comércio e serviços não tenham sido considerados, em termos de estimativa de poluentes, por falta de dados sobre emissões nestes setores, por razões justificáveis do padrão ISIC, o conceito de dependência estrutural da economia resultou também em efeitos de transbordo nesses setores. Isso se mostra óbvio, já que se utilizam insumos tecnologicamente poluentes provenientes das outras indústrias. $\mathrm{O}$ efeito marginal de um real a mais na demanda final no setor agropecuário mostrou impacto indireto na geração de $410 \mathrm{~g}$ de $\mathbf{C O}, 390 \mathrm{~g}$ de $\mathbf{S O}_{2}, 350 \mathrm{~g}$ de TSS e $320 \mathrm{~g}$ de poluentes tóxicos. Embora não se tenham averiguado os impactos diretos na estrutura inicial desses setores, a reação é da emis- 
são de algum volume de metais tóxicos. De maneira geral, o impacto total de consumo de uma unidade monetária resultou na emissão total de $2,15 \mathrm{~kg}$ de diferentes poluentes industriais na agropecuária. Tal como a agropecuária, no setor extrativo mineral, os efeitos indiretos foram de $1430 \mathrm{~g}$ de TSS, $760 \mathrm{~g}$ de $\mathbf{S O}_{2}, 700 \mathrm{~g}$ de CO, $470 \mathrm{~g}$ de PT e $370 \mathrm{~g}$ de $\mathrm{NO}_{2}$, os cinco poluentes mais expressivos. O impacto indireto total foi da ordem de 4,5 kg de poluentes totais na água e no ar. Dada a repercussão estrutural desse processo de interdependência, os setores de comércio e serviços absorveram capacidade de emitirem $290 \mathrm{~g}$ de TSS e 270 $\mathrm{g}$ de $\mathbf{S O}_{2}$, num total de $1,43 \mathrm{~kg}$.

Em relação aos setores cujos coeficientes de impacto direto foram considerados, a análise versou sobre o comportamento das emissões cujos requisitos diretos e indiretos advêm de choque monetário na demanda final. Assim, em se tratando de TSS, o Quadro 3 apresenta a seguinte distribuição: $21,90 \mathrm{~kg}$, por real, de demanda final do setor de siderurgia e metalurgia, $3,36 \mathrm{~kg}$ no setor de materiais eletroeletrônicos, 3,12 kg no setor outras indústrias, $2,83 \mathrm{~kg}$ no setor de farmacêutica e veterinária, e $2,74 \mathrm{~kg}$ no setor de transportes, máquinas e equipamentos. No caso de metais tóxicos, foram relevantes os setores de siderurgia e metalurgia, $1,07 \mathrm{~kg}$; materiais eletroeletrônicos, 210 g; e o setor de transportes, máquinas e equipamentos, $160 \mathrm{~g}$. Quanto à demanda bioquímica de oxigênio, os setores de madeira, mobiliário, papel celulose e gráfica, com 580 g, alimentos processados, com 420 g, e siderurgia e metalurgia, com 310 $\mathrm{g}$, foram os que apresentaram impactos relevantes. Finalmente, a análise de CO demonstrou que os setores de siderurgia e metalurgia, com $4,80 \mathrm{~kg}$, química e petroquímica, com $3,21 \mathrm{~kg}$, madeira, papel e celulose, com 2,12 kg, outras indústrias, com 1,05 kg e materiais eletroeletrônicos, com $1,12 \mathrm{~kg}$, apresentaram os maiores efeitos multiplicadores de demanda. A consistência dos requisitos diretos e indiretos da poluição pode ser melhor visualizada por meio dos multiplicadores que estimam os efeitos totais de mudanças exógenas sobre as principais variáveis macroeconômicas. Mediante esse recurso, foram estimados os multiplicadores setoriais da poluição industrial para a economia. 
Quadro 3-Requisitos em kg de poluentes industriais resultantes de choques na demanda final na economia brasileira

\begin{tabular}{ccccccc}
\hline \hline Tipo de & \multicolumn{5}{c}{ Setores econômicos } \\
\cline { 2 - 7 } Poluente & 1 & 2 & 3 & 4 & 5 & 6 \\
\hline \hline SO2 & 0,39 & 0,76 & 0,93 & 1,07 & 5,88 & 1,80 \\
NO2 & 0,26 & 0,37 & 0,59 & 0,64 & 1,33 & 1,11 \\
CO & 0,41 & 0,70 & 0,66 & 0,60 & 4,80 & 2,12 \\
VOC & 0,22 & 0,30 & 0,85 & 0,63 & 0,81 & 1,04 \\
PF & 0,04 & 0,11 & 0,08 & 0,23 & 0,75 & 0,24 \\
TSP & 0,11 & 0,21 & 0,29 & 0,54 & 1,32 & 0,70 \\
BOD & 0,05 & 0,06 & 0,10 & 0,42 & 0,31 & 0,58 \\
TSS & 0,35 & 1,43 & 0,69 & 1,13 & 21,90 & 2,71 \\
Poluentes Tóxicos & 0,32 & 0,47 & 1,73 & 0,41 & 2,35 & 0,94 \\
Metais Tóxicos & 0,02 & 0,08 & 0,10 & 0,04 & 1,07 & 0,05 \\
SO2 & 2,65 & 4,75 & 1,22 & 1,43 & 0,98 & 0,27 \\
NO2 & 1,91 & 3,20 & 0,51 & 0,56 & 0,60 & 0,17 \\
CO & 3,21 & 1,05 & 1,12 & 1,07 & 0,72 & 0,21 \\
VOC & 1,56 & 0,45 & 0,58 & 0,73 & 0,50 & 0,11 \\
PF & 0,17 & 3,50 & 0,18 & 0,15 & 0,11 & 0,08 \\
TSP & 0,64 & 2,81 & 0,32 & 0,34 & 0,28 & 0,10 \\
BOD & 0,22 & 0,05 & 0,08 & 0,07 & 0,11 & 0,03 \\
TSS & 1,47 & 3,12 & 3,36 & 2,74 & 2,83 & 0,29 \\
Poluentes Tóxicos & 2,54 & 0,52 & 1,09 & 0,81 & 1,12 & 0,15 \\
Metais Tóxicos & 0,12 & 0,11 & 0,21 & 0,16 & 0,05 & 0,01 \\
\hline Eoryyyyyy Cón & & & & \\
\hline
\end{tabular}

Fonte: Cálculos da pesquisa.

O conceito de multiplicador aplicado à análise de poluição pode ser de grande utilidade e representaria um importante instrumento para a tomada de decisões concernentes às diretrizes de políticas de controle de poluição industrial. O conceito pode ser usado para determinar o nível de taxação e mecanismos de licenciamentos negociáveis ou outros instrumentos de controle que visem reduzir e controlar o nível das emissões. No caso da poluição industrial, multiplicadores maiores associam-se àqueles setores intensivos em tecnologias "sujas". Conforme Figura 2, os cinco setores identificados como os de maior dinâmica na poluição fo- 
ram a siderurgia e metalurgia (setor 5), 40,5; outras indústrias (8), 19,6; química e petroquímica (7), 14,5; madeira, mobiliário, papel e celulose (10), 11,29; e materiais eletroeletrônicos (11), 8,7.

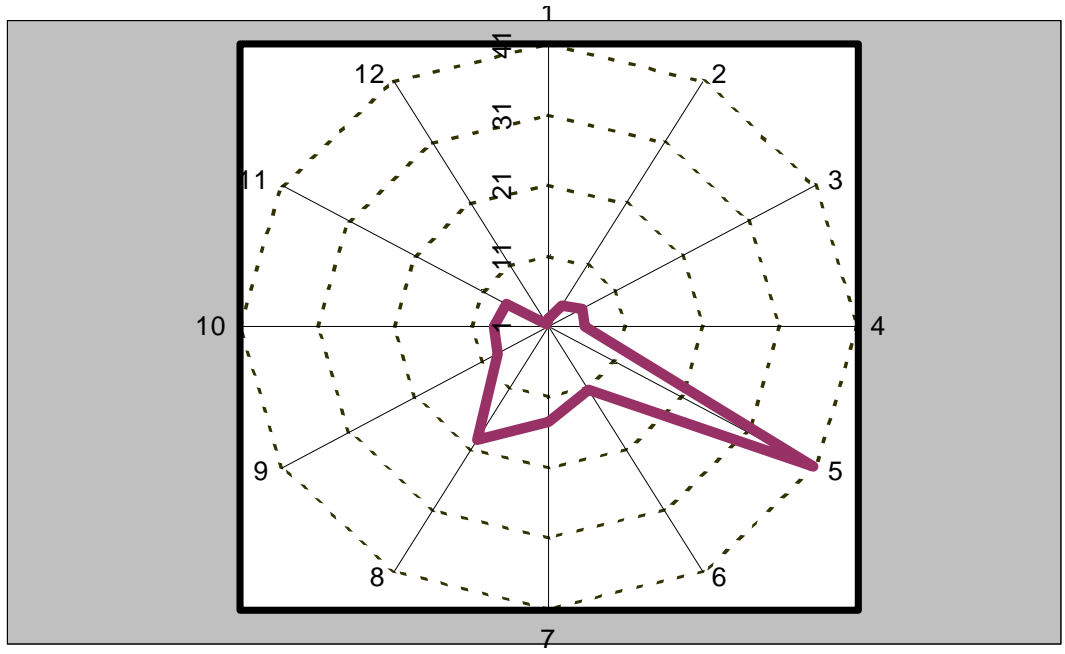

Figura 2 - Multiplicadores setoriais da poluição na economia brasileira.

Com base nesses resultados, foram elaborados cenários analíticos de choques alternativos de políticas econômicas com repercussões na estrutura produtiva e no quadro ambiental: 1) choque de $15 \%$ na demanda dos setores de siderurgia e metalurgia e química e petroquímica, identificados com maiores índices de ligações para frente e para trás e campo de influência; 2) choque de $15 \%$ na demanda final dos setores agropecuário e alimentos processados; 3) choque de $15 \%$ na demanda dos setores de madeira, papel e celulose e transportes e máquinas; 4) crescimento econômico geral de 5\% na economia. Os resultados do Quadro 4 permitem inferir que as diferentes alternativas adotadas na perspectiva de maior dinâmica na economia geram efeitos ambientais adversos na arquitetura de geração e controle de poluição. Políticas que estimulam o crescimento da demanda nos setores de siderurgia e metalurgia e química e petroquímica estimulam positivamente, a produção agregada em 7,2 bilhões de reais, com impactos na emissão total de 
84.043 toneladas de poluentes adicionais. Choques na demanda dos setores agropecuários e de alimentos processados estimulam o crescimento da economia em 28,8 bilhões de reais e geram impactos de, aproximadamente, 60.000 toneladas de poluentes da água e do ar. Em relação à estratégia política anterior, verifica-se ganho relativo de bem-estar como um todo, já que as elevações no valor total da renda e redução na emissão de poluentes traduzem benefícios sociais líquidos decorrentes dessa política.

Choques de $15 \%$ nas demandas simultâneas dos setores de madeira, papel e celulose, e transportes, máquinas e equipamentos indicam incremento de 19,7 bilhões na produção e emissões totais de 86.321 ton., enquanto o crescimento geral de $5 \%$ na economia estimularia ganhos líquidos de 55,7 bilhões de reais na renda e a emissão de 202.258,4 ton. de poluentes. Portanto, esta última estratégia segue a trajetória de expansão econômica desvantajosa em bem-estar, já que a preferência social é de que a economia se expanda com menor capacidade de poluição. 


\section{Quadro 4 - Ganhos e perdas líquidos resultantes de choques macroeconômicos (1.000 Reais)}

\begin{tabular}{|c|c|c|c|c|c|c|}
\hline Ordem & Setores & $\begin{array}{l}\text { Valor bruto da } \\
\text { produção } \\
\text { original }\end{array}$ & $\begin{array}{c}\text { GL de choque } \\
\text { de } 15 \% \text { setores } \\
5 \text { e } 7\end{array}$ & $\begin{array}{c}\text { GL de choque de } \\
15 \% \text { setores } \\
1 \text { e } 4\end{array}$ & $\begin{array}{c}\text { GL de choque } \\
\text { de } 15 \% \text { setores } \\
6 \text { e } 10\end{array}$ & $\begin{array}{c}\text { GL de choque } \\
\text { geral } \\
\text { de } 5 \%\end{array}$ \\
\hline 1 & Agropecuária & $83.299 .692,0$ & $192.303,0$ & $10.144 .409,6$ & $369.206,9$ & $4.164 .984,6$ \\
\hline 2 & Extrativo mineral & $24.983 .805,0$ & $298.820,2$ & $321.084,5$ & $271.908,9$ & $1.249 .190,2$ \\
\hline 3 & Têxteis, couros e vestuários & $31.046 .827,0$ & $33.317,4$ & $178.742,4$ & $119.334,4$ & $1.552 .341,3$ \\
\hline 4 & Alimentos processados & $86.528 .146,0$ & $64.479,8$ & $11.175 .698,4$ & $126.616,8$ & $4.326 .407,3$ \\
\hline 5 & Siderurgia e metalurgia & $50.696 .407,0$ & $2.382 .085,9$ & $493.952,3$ & $1.718 .281,4$ & $2.534 .820,3$ \\
\hline 6 & Madeira, papel e celulose & $30.984 .835,0$ & $76.349,4$ & $341.342,2$ & $2.282 .150,1$ & $1.549 .241,7$ \\
\hline 7 & Química e petroquímica & $79.358 .048,0$ & $2.775 .272,4$ & $1.926 .510,4$ & $1.705 .056,0$ & $3.967 .902,4$ \\
\hline 8 & Outras indústrias & $97.979 .867,0$ & $52.285,0$ & $100.753,8$ & $135.967,8$ & $4.898 .993,3$ \\
\hline 9 & Materiais eletro-eletrônicos & $26.969 .733,0$ & $22.981,8$ & $37.742,3$ & $126.875,8$ & $1.348 .486,6$ \\
\hline 10 & Transp., máquinas, equip. & $98.934 .108,0$ & $348.012,9$ & $940.636,2$ & $10.137 .460,4$ & $4.946 .705,4$ \\
\hline 11 & Farmacêutica e veterinária & $9.804 .824,0$ & $5.719,7$ & $49.047,3$ & $7.969,1$ & $490.241,2$ \\
\hline \multirow[t]{13}{*}{12} & Comércio e serviços & $492.765 .334,0$ & $914.376,7$ & $3.084 .837,3$ & $2.690 .469,4$ & $24.638 .266,7$ \\
\hline & "Valor bruto produção & 1.113.351.626 & 7.166 .004 & 28.794.757 & 19.691.297,8 & $\overline{55.667 .581,3}$ \\
\hline & $\begin{array}{l}\text { Tipo de poluente } \\
\text { (Toneladas) }\end{array}$ & & & & & \\
\hline & SO2 & $803.280,20$ & $12.942,84$ & $11.049,81$ & $14.736,4$ & $40.164,0$ \\
\hline & NO2 & $477.571,59$ & $5.317,31$ & $6.716,39$ & $6.408,0$ & $23.878,5$ \\
\hline & CO & $414.322,53$ & $12.473,61$ & $7.095,15$ & $12.334,8$ & $20.716,1$ \\
\hline & VOC & $228.909,85$ & $3.970,90$ & $6.491,41$ & $7.744,9$ & $11.445,4$ \\
\hline & Partículas Finas & $363.237,95$ & $1.345,72$ & $2.149,62$ & $1.600,3$ & $18.161,9$ \\
\hline & Partículas susp. (TSP) & $368.791,16$ & $2.994,93$ & $5.188,54$ & $3.933,9$ & $18.439,5$ \\
\hline & BOD & $59.821,42$ & 820,98 & $3.871,39$ & $1.536,7$ & $2.991,0$ \\
\hline & TSS & $942.872,42$ & $32.886,09$ & $11.443,39$ & $26.998,6$ & $47.143,6$ \\
\hline & Poluentes tóxicos & $297.412,84$ & $7.889,45$ & $5.028,49$ & $8.185,9$ & $14.870,6$ \\
\hline & Metais tóxicos & $44.474,20$ & $1.700,61$ & 475,77 & $1.420,6$ & $2.223,7$ \\
\hline & Poluição total & 4.045.168,40 & $84.043,00$ & $\mathbf{5 9 . 9 8 5 , 7 0}$ & $86.321,3$ & 202.258,4 \\
\hline
\end{tabular}

Fonte: Resultados da pesquisa.

Na perspectiva dessas quatro medidas de políticas, a injeção de maior dinâmica nos setores da agropecuária e de alimentos processados apresentou os melhores indicadores de desempenho monetário para a economia, além de ter possibilitado menores quantidades relativas de emissões poluentes. Entretanto, essas medidas de políticas seriam consideradas cenários sensíveis, já que justamente no setor agropecuário não foram considerados os coeficientes de impacto direto de emissões. 


\section{Considerações Finais}

Foram identificadas cinco indústrias dinâmicas na emissão de poluentes no Brasil. A siderurgia e metalurgia, outras indústrias, química e petroquímica, madeira, mobiliário, papel e celulose, e materiais eletroeletrônicos apresentaram expressivos multiplicadores de emissão de poluentes resultante de choques na demanda final. Com base nos cenários analisados, observou-se que os choques de consumo nos setores da agropecuária e de alimentos processados estimulariam o crescimento econômico em 28,8 bilhões de reais e gerariam impactos na emissão total no ar e na água em cerca de 60.000 ton. Considerando-se todos os cenários construídos, a injeção nos setores da agropecuária e de alimentos processados apresentou os melhores indicadores de desempenho macroeconômico e possibilitou menores quantidades de emissões. Desse modo, os resultados obtidos permitem concluir que a definição de estratégias de desenvolvimento econômico que levem em consideração a análise da dimensão ambiental, especificamente em termos de poluição, pode levar à obtenção de melhores resultados para o bem-estar social. Os objetivos de redução ou de expansão dos níveis de emissões poluentes dependerão de cenários de políticas governamentais e macroeconômicas a serem adotadas.

\section{Referências Bibliográficas}

BULMER-THOMAS, V. Input-output analysis in development countries. Sources methods and applications. London, John willey \& Sons LTD, 1982.

DORFMAN, R., SAMUELSON. P. A., SOLOW, R. M. Programación Lineal y Analisis Económico. Madrid: Ed. Aguilar, 572p. 1964.

HAWKINS, D., SIMON, H. A. Some condictions of macroeconomic stability. Econometrica, 17 (jul/out 1949), p. 245 - 48. 
HETTIGE, H.; MARTIN, P.; SINGH, M.; WHEELER, D. The industrial pollution projection system. Policy research working paper \# 1431 (part 1), World Bank, December, 1994, 14 p.

LEONTIEF, W. Environmental repercussions and economic structure: an input-output approach. The Review of Economics and Statistics. v. 3, p.262 - 71, (August, 1970).

LEONTIEF, W. Environmental repercussions and economics structure: an input-output approach: "A Reply". The Review of Economics and Statistics. v. 57 p. 109-110, 1974.

LEE, K-SOO. A Generalized input-output model of an economy with environmental protection. The Review of Economics and Statistics. v. 64, n.3, p. 466-73, (August, 1982).

MIERNYK, W. H. Elementos de análise do insumo-produto. São Paulo: Atlas, 1974, 164p.

MILLER, R. E., BLAIR, P. D. Input-output analysis: Foundations and Extensions. New Jersey: Prentice Hal, Inc. Englewood Cliffs, 1985.

RICHARDSON, H. W. Input-output and regional economics. First ed. Weidenfeld \& Nicolson, London, 1972.

SOLOW, R. On the structure of linear models. Econometrica, XX (jan 1952), p. $29-46$.

VICTOR, P. A. Economics of pollution. The Macmillan Press Ltd. London. 1972, 78p. 
REVISTA DE ECONOMIA E AGRONEGÓCIO, VOL.1, $N^{o} 2$ 